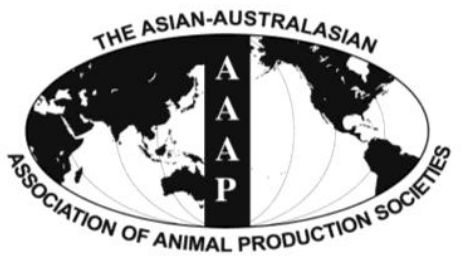

Asian-Aust. J. Anim. Sci.

Vol. 26, No. 4 : 517-522 April 2013

http://dx.doi.org/10.5713/ajas.2012.12480

Www.ajas.info

pISSN $1011-2367$ elSSN 1976-5517

\title{
The Effect of Plant Extracts on In-vitro Ruminal Fermentation, Methanogenesis and Methane-related Microbes in the Rumen
}

\author{
E. T. Kim, K. -S. Min ${ }^{1}$, C. -H. Kim², Y. H. Moon ${ }^{3}$, S. C. Kim ${ }^{4}$ and S. S. Lee* \\ Division of Applied Life Science (BK21 program), Gyeongsang National University \\ (Institute of Agriculture and Life Science), Jinju, 660-701, Korea
}

\begin{abstract}
The effect on methanogens attached to the surface of rumen ciliate protozoa by the addition of plant extracts (pine needles and ginkgo leaves) was studied with particular reference to their effectiveness for decreasing methane emission. The plant extracts (pine needles and ginkgo leaves) were added to an in vitro fermentation incubated with rumen fluid. The microbial population including bacteria, ciliated-associated methanogen, four different groups of methanogens and Fibrobacter succinogenes were quantified by using the real-time PCR. Gas profiles including methane, carbon dioxide and hydrogen, and runinal fermentation characteristics were observed in vitro. The methane emission from samples with an addition of individual juices from pine needles, ginkgo leaves and $70 \%$ ethanol extract from ginko leaves was significantly lower ( $<<0.05,27.1,28.1$ and $28.1 \mathrm{vs} 34.0 \mathrm{ml} / \mathrm{g} \mathrm{DM}$ ) than that of the control, respectively. Total VFAs in samples with an addition of any of the plant extracts were significantly lower than that of the control $(\mathrm{p}<0.05)$ as well. The order Methanococcales and the order Methanosarcinales were not detected by using PCR in any incubated mixtures. The ciliate-associated methanogens population decreased from $25 \%$ to $49 \%$ in the plant extacts as compared to control. We speculate that the supplementation of juice from pine needles and ginkgo leaves extract (70\% ethanol extract) decreased the protozoa population resulting in a reduction of methane emission in the rumen and thus inhibiting methanogenesis. The order Methanobacteriales community was affected by addition of all plant extracts and decreased to less than the control, while the order Methanomicrobiales population showed an increase to more than that of the control. The $F$. succinogenes, the major fibrolytic microorganism, population in all added plant extracts was increased to greater than that of the control. In conclusion, pine needles and ginkgo leaves extracts appear to have properties that decrease methanogenesis by inhibiting protozoa species and may have a potential for use as additives for ruminants. (Key Words: Methane Emission, Relative Quantification, Real-time PCR, Pine Neddle, Ginkgo Leaf)
\end{abstract}

\section{INTRODUCTION}

Global warming due to increased atmospheric concentration of greenhouse gases including methane is a major interest in recent years. Methane emission from livestock industries, in particular from ruminants, is a significant contributor to this problem. Methane is a 23

\footnotetext{
* Corresponding Author: Sung-Sill Lee. Tel: +82-55-772-1883, Fax: +82-55-772-1889, E-mail: lss@gnu.ac.kr

${ }^{1}$ Animal Biotechnology, GSBIT, Hankyong National University, Anseong, 441-560, Korea.

${ }^{2}$ School of Animal Life and Environment Science, Hankyong National University, Anseong, 456-749, Korea.

${ }^{3}$ Department of Animal Science \& Biotechnology, Gyeongnam National University of Science and Technology, Jinju, 660-758, Korea.

${ }^{4}$ Department of Animal Science, Gyeongsang National University (Institute of Agriculture and Life Science), Jinju, 660-701, Korea. Submitted Sept. 6, 2012; Accepted Oct. 25, 2012; Revised Dec. 12, 2012
}

times more potent green house gas than carbon dioxide (IPPC, 2007). Methane emission related to enteric fermentation from ruminants is mostly due to the optimal anaerobic conditions for facultative the growth of bacteria, protozoa and fungi. Methane emission in the rumen is considered an energetically wasteful process as it causes a substantial loss of $12 \%$ of the dietary energy intake (Johnson et al., 1995). Many chemical dietary additives have been examined for their potential to reduce methane emissions in the rumen, but were either toxic to host animals or caused side effects on beneficial ruminal microbes (Martin and Macy, 1985; Van Nevel and Demeyer, 1988; Moss, 1993; Van Nevel and Demeyer, 1996). The selection of bio-active compounds for the elimination of protozoa has been an approach studied with the aim of reducing methane emission from ruminants. However, the risk of using chemicals in animals destined for human consumption is of growing public concern. In the previous 
study, Kim et al. (2012) showed that plant extracts were good alternative candidates to manipulate rumen microbial diversity with the goal of reducing methane emission. This approach has been set as one of the most important goals for animal nutritionists (Teferedegne, 2000).

The objective of this study was to evaluate the in vitro effect of pine needle and ginkgo leaves extracts on ruminal fermentation, rumen methanogenesis and methane-related microbes.

\section{MATERIALS AND METHODS}

\section{In vitro incubation}

Animal: A fistulated Holstein cow of $500 \mathrm{~kg}$ body weight was used as a donor of rumen fluid. Timothy and commercial concentrate (TDN; $73.5 \%$, crude protein; $19 \%$, crude fat; $3 \%$, crude fiber; $12 \%$, crude ash; $10 \%$, Ca; $0.8 \%$, $\mathrm{P} ; 1.2 \%$, AMINOTEK, CJ feeds) in the ratio of 60:40 were fed at $2 \%$ of body weight twice a day. Water and mineralvitamin block were allowed ad libitum.

Rumen fluid: The rumen fluid was collected from the fistulated Holstein cow before morning feeding. Rumen samples were collected in a bottle, previously kept warm and filled with $\mathrm{O}_{2}$ free- $\mathrm{CO}_{2}$ gas, carried to the laboratory, and filtered through four layers of cheesecloth before mixing with buffer maintained at $39^{\circ} \mathrm{C}$ and under $\mathrm{O}_{2}$-free $\mathrm{N}_{2}$ gas.

Preparation of extract: Pine (Pinus densiflora) needles and ginkgo (Ginkgo biloba L.) leaves extracts were prepared in $70 \%$ ethanol at $100 \mathrm{~g} / 300 \mathrm{ml}$ of solvent. The flasks of $70 \%$ ethanol were stoppered and incubated at $39^{\circ} \mathrm{C}$ on a rotary shaker (HBS-201SL, HANBAEK, Korea) for 24 h. Juice from pine needles and ginkgo leaves were prepared by extraction from crushed leaves. The extracts were then filtered through filter paper (Whatman No. 1). The filtrates were then collected and the solvent, $70 \%$ ethanol, removed using a rotary evaporator, and stored at $4{ }^{\circ} \mathrm{C}$ for further use.

In vitro incubation: Four extracts were prepared for their effects on ruminal methanogenesis and fermentation. Treatment designations were non-additives (Control), T1 (5\% of juice from pine needles), T2 (5\% of $70 \%$ ethanol extract from pine needles), T3 (5\% of juice from ginkgo leaves) and T4 (5\% of 70\% ethanol extract from ginkgo leaves). Rumen liquor was filtered through four layers of cheesecloth before mixing with buffer maintained at $39^{\circ} \mathrm{C}$. The $30 \mathrm{ml}$ of rumen fluid-buffer mixture, comprising McDougall buffer and rumen liquor in the ratio of 4 to 1 , was dispensed anaerobically into $120 \mathrm{ml}$ serum bottles, filled with $\mathrm{O}_{2}$-free $\mathrm{N}_{2}$ gas, containing $0.3 \mathrm{~g}$ of timothy substrate and plant extracts $(5 \%$ of total volume of rumen fluid-buffer mixture (v/v), respectively), and then capped with a rubber stopper. The serum bottles were held in a shaking incubator (HBS-201SL, HANBAEK, Korea) at $39^{\circ} \mathrm{C}$ for $24 \mathrm{~h}$. The in vitro experiment were evaluated in triplicate run for analysis of gas proflies and VFAs.

\section{Analyses}

Total gas production was measured by the assay of Theodorou et al. (1994). A detachable pressure transducer and a digital readout voltmeter (Laurel Electronics, Inc., CA USA) were used to measure the headspace gas pressure of fermenting cultures. The transducer was modified to link to the inlet of a disposable Luer-lock three-way stopcock in other to measure total gas production in the system (Theodorou, 1994). Gas pressure in the headspace was read from the display unit after insertion of a hypodermic syringe needle through the butyl rubber stopper above the culture medium. The headspace gas in the serum bottle was collected for analysing the composition of gases, focusing on methane, carbon dioxide and hydrogen. These three gases were analysed using gas chromatography (GC-2010, Shimadzu, Japan) equipped with column (Shincarbon ST. 50/80, Shimadzu, Japan). The incubated inoculum was subsampled for the analysis of $\mathrm{pH}$ (Mettle-Toledo, $\mathrm{CH} / \mathrm{MP} 220$ ), volatile fatty acid (VFA) concentration and gDNA extraction. VFA analysis was performed with a gas chromatography (GC-2010, Shimadzu, Japan) as described by Erwin et al. (1961).

\section{DNA extraction, PCR primers and Real-time PCR}

DNA extraction: TissueLyser (Retsch; QIAGEN, Valencia, CA), a high-speed reciprocal shaker which retains samples in screw-capped tubes containing silica beads, was used for DNA extraction. Total nucleic acid was extracted from the incubated rumen samples by using the modified bead-beating protocol with the QIAamp DNA mini kit (250) (QIAGEN, USA). For samples a $1.0 \mathrm{ml}$ aliquot was taken from the $30 \mathrm{ml}$ incubated mixture using a wide bore pipette so as to ensure a homogenous sample containing fluid and digesta. Nucleic acid concentrations were measured by using a NanoDrop Spectrophotometer (ND1000, USA).

PCR primers: The PCR primer sets used in this study for amplification of general bacteria, Fibrobacter succinogenes, archaea, methanogenic archaea, ciliateassociated methanogen and four different groups of methanogens (the order Methanobacteriales, the order Methanomicrobiales, the order Methanosarcinales and the order Methanococcales) were the same as referenced by Denman and McSweeney (2006), Tajima et al. (2001), Ohene-Adjei et al. (2008), Luton at al. (2002), Medlin et al. (1998) and Yu et al. (2005), respectively as shown in Table 1.

Real-time PCR: PCR assays for the enumeration of 
Table 1. Oligonucleotide primers used for (q)PCR assay

\begin{tabular}{|c|c|c|c|}
\hline Target group & Sequence $\left(5^{\prime}-3^{\prime}\right)$ & $\begin{array}{l}\text { Amplification } \\
\text { size (bp) }\end{array}$ & Reference \\
\hline General bacteria* & CGCCAACGAGCGCAACCC / CCATTGTAGCACGTGTGTAGCC & 130 & $\begin{array}{c}\text { Denman and McSweeney } \\
\text { (2006) }\end{array}$ \\
\hline Fibrobacter succinogenes* & GGTATGGGATGAGCTTGC / GCCTGCCCCTGAACTATC & 445 & Tajima et al. (2001) \\
\hline Archaea $^{\mathrm{a}}$ & GAGGAAGGAGTGGACGACGGTA / ACGGGCGGTGTGTGCAAG & 233 & Ohene-Adjei et al. (2008) \\
\hline Methanogenic archaea* & $\begin{array}{l}\text { GGTGGTGTMGGATTCACACARTAYGCWACAGC/ } \\
\text { TTCATTGCRTAGTTWGGRTAGTT }\end{array}$ & 440 & Luton et al. (2002) \\
\hline Ciliate-associated methanogens* & AGGAATTGGCGGGGGAGCAC / TGTGTGCAAGGAGCAGGGAC & 412 & Medlin et al. (1988) \\
\hline Methanobacteriales $^{\mathrm{a}, *}$ & CGWAGGGAAGCTGTTAGT / TACCGTCGTCCACTCCTT & 343 & Yu et al. (2005) \\
\hline Methanomicrobiales $^{\mathrm{a}, *}$ & ATCGRTACGGGTTGTGGG / CACCTAACGCRCATHGTTTAC & 506 & Yu et al. (2005) \\
\hline Methanosarcinales ${ }^{\mathrm{a}, *}$ & GTAAACGATRYTCGCTAGGT / GGTCCCCACAGWGTACC & 354 & Yu et al. (2005) \\
\hline Methanococcales $^{\mathrm{a}, *}$ & TAAGGGCTGGGCAAGT / CACCTAGTYCGCARAGTTTA & 337 & Yu et al. (2005) \\
\hline
\end{tabular}

All primers were amplified by PCR for proper primers selection (data not shown).

a PCR amplification (Figure 1). * Real-time PCR amplification.

ciliate-associated methanogens, four different groups of methanogens and cellulolytic bacterial species were performed according to the methods described by Denman and McSweeney (2006) and Denman et al. (2007) on a Rotor-Gene Real-Time PCR Machine (Crobett life science, Australia) using the iQ SYBR Green Supermix (Bio-Rad Inc. USA). The values of cycle threshold $(\mathrm{Ct})$ after realtime PCR were used to determine fold change (number of fold difference) of different microbial population relative to control without plant extract and plant extracts treatments. Abundance of these microbes was expressed by the equation: relative quantification $=2^{-\Delta \mathrm{Ct}(\text { Target })-\Delta \mathrm{Ct}(\text { Control })}$, where $\mathrm{Ct}$ represents threshold cycle. All quantative (q) PCR reaction mixture (final volume of $25 \mu \mathrm{l}$ ) contained forward and reverse primers, the iQ SYBR Green Supermix and DNA template ranging from $10 \mathrm{ng}$ to $100 \mathrm{ng}$. A negative control without the template DNA was used in every qPCR assay for each primer. The PCR conditions for the amplification of target DNA, including the annealing and the extension temperature, were tested before application as shown in following references (Table 1).

\section{Statistical analysis}

Data were analyzed using the general linear model (GLM) procedure of the Statistical Analysis System Institute, Inc. (SAS, 2002). Differences among means were tested for significance using Duncan's multiple range test of SAS (2002).

\section{RESULTS AND DISCUSSION}

\section{Ruminal fermentation characteristics}

The in vitro total gas production, methane emission and carbon dioxide production are shown in Table 2. Pine needles and ginkgo leaves extracts affected total gas production as well as methane emission and carbon dioxide production in the rumen. Total gas production in samples with added pine needles and ginkgo leaves extracts were lower than that of the control (Table 2). The in vitro ruminal fermentation might be affected by the dosage of plant extracts as well as the extract solvents (Patra et al., 2010). Pfister et al. (1992) also suggested that $15 \%$ to $30 \%$ pine needles in cattle diets appears to be the threshold level for toxic effects on ruminal fermentation. However, adverse effects of plant extracts on digestive performance in cattle should be considered for further studies. The methane emission in samples with pine needles juice and ginkgo leaves extracts added ( $70 \%$ ethanol extract and juice) were significantly lower ( $\mathrm{p}<0.05,27.1,28.1$ and 28.1 vs 34.0 $\mathrm{ml} / \mathrm{g} \mathrm{DM}$ ) than that of the control. The $\mathrm{pH}$ in addition of ginkgo leaves extracts was significantly affected $(\mathrm{p}<0.05$, Table 3). Total VFAs in addition of all plant extracts were significantly lower than that of the control $(\mathrm{p}<0.05$, Table 3$)$. Although $\mathrm{H}_{2}$ was analyzed by gas chromatography (GC2010, Shimadzu, Japan), it was not detected. This possibly indicates that $\mathrm{H}_{2}$ products might have been utilised as a substrate for transfer of $\mathrm{CH}_{4}$ by methanogens in the rumen. Thus, $\mathrm{H}_{2}$ could be of critical concern to the microbial

Table 2. The effect of pine needles and ginkgo leaves extracts on in-vitro total gas, $\mathrm{CH}_{4}$ and $\mathrm{CO}_{2}$ productions after $24 \mathrm{~h}$ incubation

\begin{tabular}{|c|c|c|c|c|c|c|}
\hline & Control & $\mathrm{T} 1$ & $\mathrm{~T} 2$ & T3 & $\mathrm{T} 4$ & SEM \\
\hline Total gas (ml/g DM) & $233.1^{\mathrm{a}}$ & $209.1^{\mathrm{c}}$ & $225.1^{\mathrm{b}}$ & $201.8^{\mathrm{c}}$ & $202.9^{c}$ & 3.44 \\
\hline $\mathrm{CH}_{4}(\mathrm{ml} / \mathrm{g} \mathrm{DM})$ & $34.0^{\mathrm{a}}$ & $27.1^{b}$ & $32.3^{\mathrm{a}}$ & $28.1^{\mathrm{b}}$ & $28.1^{b}$ & 0.83 \\
\hline $\mathrm{CO}_{2}(\mathrm{ml} / \mathrm{g} \mathrm{DM})$ & $129.3^{\mathrm{a}}$ & $89.0^{c}$ & $113.6^{\mathrm{ab}}$ & $96.1^{\mathrm{bc}}$ & $86.6^{\mathrm{c}}$ & 4.82 \\
\hline
\end{tabular}

a, b, c Means within a row with different superscripts differ significantly $(\mathrm{p}<0.05)$.

Control: no additive, T1: $5 \%$ of juice from pine needles, T2: $5 \%$ of $70 \%$ ethanol extract from pine needles, T3: 5\% of juice from ginkgo leaves, T4: 5\% of $70 \%$ ethanol extract from ginkgo leaves. 
Table 3. The effect of pine needles and ginkgo leaves extracts on in-vitro ruminal fermentation characteristics after $24 \mathrm{~h}$ incubation

\begin{tabular}{lrrrrrr}
\hline & Control & T1 & T2 & T3 & T4 & SEM \\
\hline pH & $6.30^{\mathrm{c}}$ & $6.33^{\mathrm{bc}}$ & $6.31^{\mathrm{c}}$ & $6.36^{\mathrm{a}}$ & $6.35^{\mathrm{ab}}$ & 0.02 \\
tVFA $(\mathrm{mM})$ & $101.16^{\mathrm{a}}$ & $91.64^{\mathrm{b}}$ & $91.04^{\mathrm{b}}$ & $93.17^{\mathrm{b}}$ & $92.28^{\mathrm{b}}$ & 7.15 \\
Acetate $(\mathrm{mM})$ & $53.44^{\mathrm{a}}$ & $48.96^{\mathrm{b}}$ & $48.45^{\mathrm{b}}$ & $49.47^{\mathrm{ab}}$ & $48.67^{\mathrm{b}}$ & 3.67 \\
Propionate $(\mathrm{mM})$ & $27.22^{\mathrm{a}}$ & $24.37^{\mathrm{b}}$ & $24.17^{\mathrm{b}}$ & $24.99^{\mathrm{ab}}$ & $24.93^{\mathrm{ab}}$ & 2.00 \\
Butyrate $(\mathrm{mM})$ & $15.45^{\mathrm{a}}$ & $13.76^{\mathrm{b}}$ & $13.61^{\mathrm{b}}$ & $14.00^{\mathrm{b}}$ & $13.99^{\mathrm{b}}$ & 0.09 \\
A:P ratio & $1.96^{\mathrm{c}}$ & $2.01^{\mathrm{a}}$ & $2.00^{\mathrm{ab}}$ & $1.98^{\mathrm{bc}}$ & $1.95^{\mathrm{c}}$ & 0.03 \\
\hline
\end{tabular}

$\overline{a, b, c}$ Means within a row with different superscripts differ significantly $(\mathrm{p}<0.05)$.

Control: no additive, T1: $5 \%$ of juice from pine needles, T2: $5 \%$ of $70 \%$ ethanol extract from pine needles, T3: 5\% of juice from ginkgo leaves, T4: 5\% of $70 \%$ ethanol extract from ginkgo leaves.

ecosystem in ruminants. Also, the formation of propionate from succinate would result in a lower availability of $\mathrm{H}_{2}$ for methanogenesis. $\mathrm{H}_{2}$ produced during enteric fermentation is the precursor of methane in ruminants and the regulation of $\mathrm{H}_{2}$ rather than methane is the key to the control ruminant methane emission. This study showed that plant extracts, in particular ginkgo leaves extract can potentially influence methanogenesis, resulting in a reduction in methane emission from the rumen.

\section{Microbial diversity related methane emission in the rumen}

Pine needles and ginkgo leaves extracts similar to those used in the present experiment are known to have anthelmintic, antibacterial and antioxidant activities, and have been used as medicinal materials (Choi et al., 1997; Kim and Shin, 2005; Lee et al., 2006). The secondary compounds from pine needles and ginkgo leaves, such as flavonoids, might manipulate ruminal fermentation and inhibit microbes, especially protozoa, in the rumen (Figure 2). Pine needles and ginkgo leaves have been shown to possess strong antibiotic characteristics against various bacteria (Choi et al., 1997; Lee et al., 2006), in particular, ginkgo leaves extract is well known for having a natural insecticidal effect and perhaps have anthelmintic and antibacterial properties. Antioxidative activities of pine (Pinus denstifora) needle extracts have been tested in vitro experimental models by Yoo et al. (2004). The concentration of total polyphenolic compound of water

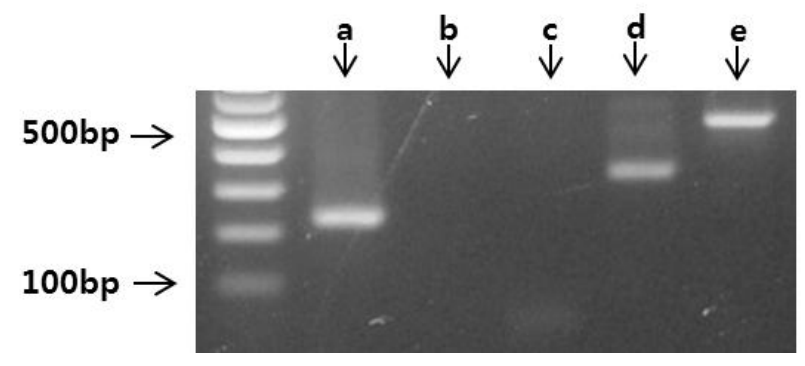

Figure 1. The PCR amplification of microbial population - related to methanogens in the rumen (a: Archaea, b: Methanococcales, c: Methanosarcinales, d: Methanobacteriales, e: Methanomicrobiales). extracts from pine needles was $1.61 \%$. This finding is in agreement with other studies where the concentration of total polyphenolic compounds are $1.80 \%$ (Kang et al., 1995), and $1.32 \%$ (Kim et al., 2000), respectively. The microbial population related to methanogens determined with PCR is shown in Figure 1. The order Methanococcales and the order Methanosarcinales were not detected in this study in any of the incubated mixtures. Behlke (2007) also could not detect these two orders (the order Methanococcales and the order Methanosarcinales) and reported that either these two orders were not in the rumen or they were less than the detection limit. The ciliateassociated methanogens population in samples containing any of the plant extracts was affected (Figure 2). The Ciliate-associated methanogens population decreased from $25 \%$ to $49 \%$ in the plant extracts compared to the control. As several rumen ciliates and methanogens are known to be symbionts (Vogels et al., 1980; Stumm et al., 1982), the result of this study also showed that the supplementation of pine needles juice and ginkgo leaves extract (70\% ethanol extract) decreased the protozoa population resulting in reduction of methane emission in the rumen (Figure 2; Table 2) and thus inhibiting methanogenesis. In a previous study, Broudiscou et al. (2000) screened plant extracts,

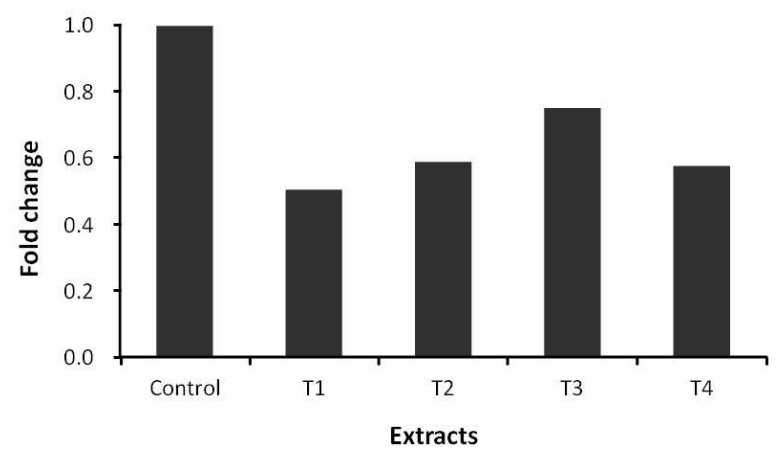

Figure 2. Relative quantification analysis of ciliate-associated methanogen community in vitro ruminal fermentation following the addition of pine needles and ginkgo leaves extracts after $24 \mathrm{~h}$ incubation (Control: no additive, T1: $5 \%$ of juice from pines needle, T2: $5 \%$ of $70 \%$ ethanol extract from pine needles, T3: $5 \%$ of juice from ginkgo leaves, T4: $5 \%$ of $70 \%$ ethanol extract from ginkgo leaves). 


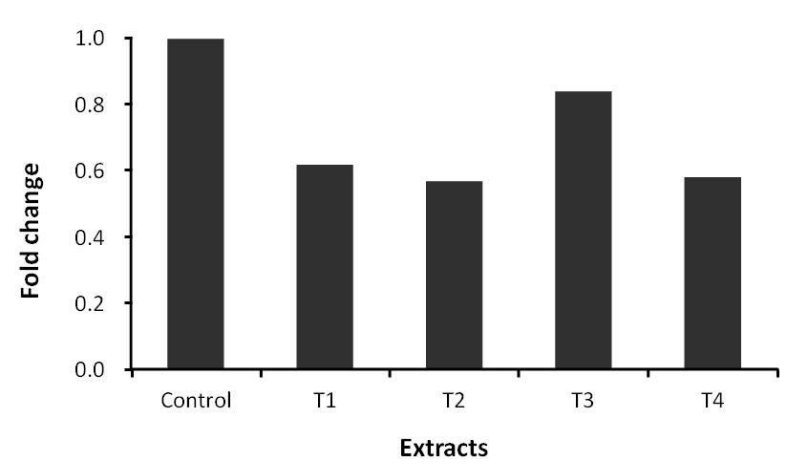

Figure 3. Relative quantification analysis of Methanobacteriales population in vitro ruminal fermentation following the addition of pine needles and ginkgo leaves extracts after $24 \mathrm{~h}$ incubation (Control: no additive, T1: $5 \%$ of juice from pines needle, T2: $5 \%$ of $70 \%$ ethanol extract from pine needles, T3: $5 \%$ of juice from ginkgo leaves, T4: $5 \%$ of $70 \%$ ethanol extract from ginkgo leaves).

selected for their high flavonoid content, on their action on methanogenesis, fermentation pattern and protozoa numbers. Broudiscou et al. (2000) reported that plant extracts slightly inhibited methanogenesis. The order Methanobacteriales community was affected by addition of all plant extracts (Figure 3). Methanobacteriales community decreased more than that of the control with addition of all plant extracts, while the order Methanomicrobiales population increased to more than that of the control (Figure 4). Plant extracts have been placed under the spotlight as a potentially useful alternative feed additives source, but there is limited data on ruminal fermentation. Compounds of selected plant extracts with known medicinal properties have been reported to interact with micro-organisms in other ecosystems, in a positive as well as in a negative way. The in vivo study by Jo et al. (1997) was conducted to evaluate the value of forages (alfalfa, acacia leaf, orchardgrass and pine needles) on feed intake and digestibility in the Korean native goat.

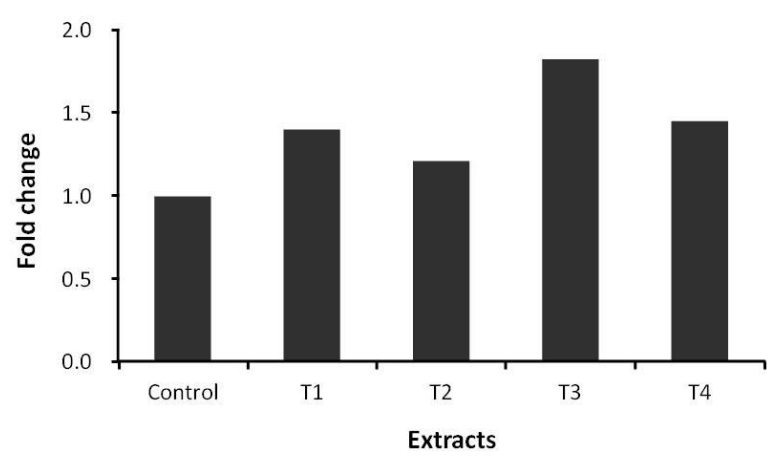

Figure 4. Relative quantification analysis of Methanomicrobiales population in vitro ruminal fermentation by following the addition of pine needles and ginkgo leaves extracts after $24 \mathrm{~h}$ incubation (Control: no additive, T1: $5 \%$ of juice from pines needle, T2: $5 \%$ of $70 \%$ ethanol extract from pine needles, T3: 5\% of juice from ginkgo leaves, T4: $5 \%$ of $70 \%$ ethanol extract from ginkgo leaves).

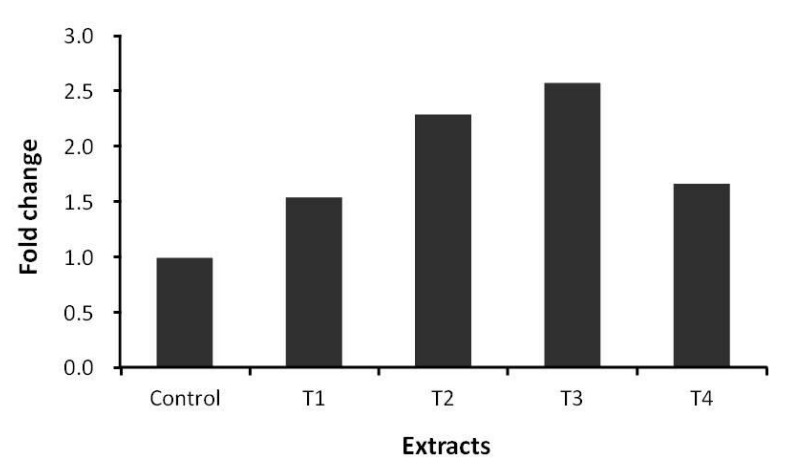

Figure 5. Relative quantification analysis of Fibrobacter succinogenes diversity in vitro ruminal fermentation following the addition of pine needles and ginkgo leaves extracts after $24 \mathrm{~h}$ incubation (Control: no additive, T1: $5 \%$ of juice from pines needle, T2: $5 \%$ of $70 \%$ ethanol extract from pine needles, T3: 5\% of juice from ginkgo leaves, T4: $5 \%$ of $70 \%$ ethanol extract from ginkgo leaves).

The result of that in vivo study showed that dry matter intake and dry matter digestibility of pine needles were lower than other forages, although the result of this in vitro study did not show an adverse effect on the F. succinogenes population by the addition of plant extracts. The $F$. succinogenes population in all added plant extracts treatments increased to greater than that of the control (Figure 5).

Plant extracts (pine needle and ginkgo leaves extracts) with known to medicineal properties used in this study were found to have properties that decreased ruminal methanogenesis and consequently, there is a need to consider the dosage of plant extracts and whether there are adverse effects of plant extracts on aspects of the ruminal fermentation in further studies.

\section{ACKNOWLEDGEMENTS}

This research was supported by Bio-industry Technology Development Program, Ministry for Food, Agriculture, Forestry and Fisheries, Korea, and E. T. Kim was supported by a scholarship from the BK21 Program, the Ministry of Education, Science and Technology, Korea.

\section{REFERENCES}

Behlke, E. J. 2007. Attenuation of ruminal methanogenesis. Theses and Dissertations in Animal Science, University of NebraskaLincoln, USA.

Broudiscoua, L. P., Y. Papon and A. F. Broudiscou. 2000. Effects of dry plant extracts on fermentation and methanogenesis in continuous culture of rumen microbes. Anim. Feed Sci. Technol. 87:263-277.

Choi, M. Y., E. J. Choi, E. Lee, T. J. Rhim, B. C. Cha and H. J. Park. 1997. Antimicrobial activities of pine needle. Korean J. Appl. Microbiol. Biotechnol. 25:293-297. 
Denman, S. E. and C. S. McSweeney. 2006. Development of a real-time PCR assay for monitoring anaerobic fungal and cellulolytic bacterial populations within the rumen. FEMS Microbiol. Ecol. 58:572-582.

Denman S. E., N. W. Tomkins and C. S. McSweeney. 2007. Quantitation and diversity analysis of ruminal methanogenic populations in response to the antimethanogenic compound bromochloromethane. FEMS Microbiol. Ecol. 62:313-322.

Erwin, E. S., G. J. Marco and E. M. Emery. 1961. Volatile fatty acid analysis of blood and rumen fluid by gas chromatography. J. Dairy Sci. 44:1768-1771.

IPCC (Intergovermental Panel on Climate Change). 2007. IPCC Fourth Assessment Report.

Irbis, C. and K. Ushida. 2004. Detection of methanogens and proteobacteria from a single cell of rumen ciliate protozoa. J. Gen. Appl. Microbiol. 50:203-212.

Jo, I. H., S. Hwangbo, K. H. Jun, H. B. Song, J. H. Ahn and J. S. Lee. 1997. The effect of roughage source on voluntary feed intake and digestibility in Korean native goats. J. Korean Grassl. Sci. 17:82-88.

Johnson, K. A. and D. E. Johnson. 1995. Methane emissions from cattle. J. Anim. Sci. 73:2483-2492.

Kang, Y. H., Y. K. Park, S. R. Oh and K. D. Moon. 1995. Studies on the physiological funtionality of pine needle and mugwort extracts. Korean J. Food Sci. Technol. 27:978-984.

Kim, E. T., C. -H. Kim, K. -S. Min and S. S. Lee. 2012. Effects of plant extracts on microbial population, methane emission and ruminal fermentation characteristics in in vitro. Asian-Aust. J. Anim. Sci. 25:806-811.

Kim, H. J., J. Y. Cha, M. L. Choi and Y. S. Cho. 2000. Antioxidative activities by water-soluble extracts of Morus alba and Cudrania tricuspidata. J. Korean Soc. Agric. Chem. Biotechnol. 43:148-152.

Kim, Y. S. and D. H. Shin. 2005. Volatile components and antibacterial effects of pine needle (Pinus densiflora S. and Z.) extracts. Food Microbiol. 22:37-45.

Lee, I. H., Y. Shim, S. H. Choi, J. Y. Park, S. W. Han, J. Y. Song and S. J. Yoon. 2006. A study on the antimicrobial effect of ginkgo bilba leaves extracts according to concentrations of ethanol for Staphylococcus aureus. Korean J. Biotechnol. Bioeng. 21:312-316.

Luton, P. E., J. M. Wayne, R. J. Sharp and P. W. Riley. 2002. The $m c r A$ gene as an alternative to 16S rRNA in the phylogenetic analysis of methanogen populations in landfill. Microbiology 148:3521-3530.

Martin, S. A. and J. M. Macy. 1985. Effects of monensin, pyromellitic diimide and 2-bromoethanesulfonic acid on rumen fermentation in vitro. J. Anim. Sci. 60:544-550.

McCrabb, G. J., K. T. Berger, T. Magner, T. May and R. A. Hunter. 1997. Inhibiting methane production in Brahman cattle by dietary supplementation with a novel compound and the effects on growth. Aust. J. Agric. Res. 48:323-329.

Medlin, L., H. J. Elwood, S. Stickel and M. L. Sogin. 1988. The characterization of enzymatically amplified eukaryotic 16Slike rRNA-coding regions. Gene. 71:491-499.

Mitsumori, M. and W. Sun. 2008. Control of rumen microbial fermentation for mitigating methane emissions from the rumen. Asian-Aust. J. Anim. Sci. 21:144-154.
Ohene-Adjei, S., A. V. Chaves, T. A. McAllister, C. Benchaar, R. M. Teather and R. J. Forster. 2008. Evidence of increased diversity of methanogenic archaea with plant extract supplementation. Microb. Ecol. 56:234-242.

Patra, A. K., D. N. Kamra and N. Agarwal. 2006. Effect of plant extracts on in vitro methanogenesis, enzyme activities and fermentation of feed in rumen liquor of buffalo. Anim. Feed Sci. Technol. 128:276-291.

Patra, A. K., D. N. Kamra and N. Agarwal. 2010. Effects of extracts of spices on rumen methanogenesis, enzyme activities and fermentation of feeds in vitro. J. Sci. Food Agric. 90:511520.

Pfister, J. A., D. C. Adams, R. D. Wiedmeier and R. G. Cates. 1992. Adverse effects of pine needles on aspects of digestive performance in cattle. J. Range Manage. 45:528-533.

SAS. 2002. SAS user's guide: Statistics. SAS Inst. Inc., Cary, NC, USA.

Stumm, C. K., H. J. Gijzen and G. D. Vogels. 1982. Association of methanogenic bacteria with ovine rumen ciliates. Br. J. Nutr. 47:95-99.

Tajima, K., R. I. Aminov, T. Nagamine, H. Matsui, M. Nakamura and Y. Benno. 2001. Diet-dependent shifts in the bacterial population of the rumen revealed with real-time PCR. Appl. Environ. Microbiol. 67:2766-2774.

Takahashi, J., B. Mwenya, B. Santoso, C. Sar, K. Umetsu, T. Kishimoto, K. Nishizaki, K. Kimura and O. Hamamoto. 2005. Mitigation of methane emission and energy recycling in animal agricultural systems. Asian-Aust. J. Anim. Sci. 18:1199-1208.

Teferedegne, B. 2000. New perspective on the use of tropical plants to improve ruminant nutrition. Proc. Nutr. Soc. 59:209214.

Van Nevel, C. J. and D. I. Demeyer. 1988. Manipulation of rumen fermentation. In The Rumen Microbial Ecosystem (Ed. P. N. Hobson) p. 387-443. Elsevier Science Publishers, New York, USA.

Van Nevel, C. J. and D. I. Demeyer. 1995. Feed additives and other interventions for decreasing methane emissions. In: Biotechnology in Animal Feeds and Animal Feeding (Ed. R. J. Wallace and A. Chesson). VCH, Weinheim, p 329-349.

Van Nevel, C. J. and D. I. Demeyer. 1996. Control of rumen methanogenesis. Environ. Monit. Assessm. 42:73-97.

Vogels, G. D., W. F. Hoppe and C. K. Stumm. 1980. Association of methanogenic bacteria with rumen ciliates. Appl. Environ. Microbiol. 40:608-612.

Wang, C. J., S. P. Wang and H. Zhou. 2009. Influences of flavomycin, ropadiar, and saponin on nutrient digestibility, rumen fermentation, and methane emission from sheep. Anim. Feed Sci. Technol. 148:157-166.

Yoo, J. H., J. Y. Cha, Y. K. Jeong, K. T. Chung and Y. S. Cho. 2004. Antioxidative Effects of Pine (Pinus denstifora) Needle Extracts. J. Life Sci. 14:863-867.

Yu, Y., C. Lee, J. Kim and S. Hwang. 2005. Group-specific primer and probe sets to detect methanogenic communities using quantitative real-time polymerase chain reaction. Biotechnol. Bioeng. 89:670-679. 